\title{
Air quality in a tourist seashore city during vacation
}

\author{
N. Quaranta ${ }^{1}$, M. Unsen ${ }^{1}$, M. Caligaris ${ }^{1}$, S. Ringler ${ }^{1}$, S. Mendiara ${ }^{2}$ \\ \& M. García ${ }^{3}$ \\ ${ }^{1}$ Grupo de Estudios Ambientales, Facultad Regional San Nicolás, \\ Universidad Tecnológica Nacional, Argentina \\ ${ }^{2}$ Departamento de Química, Facultad de Ciencias Exactas y Naturales, \\ Universidad Nacional de Mar del Plata, Argentina \\ ${ }^{3}$ Departamento de Geografia, Facultad de Humanidades, \\ Universidad Nacional de Mar del Plata, Argentina
}

\begin{abstract}
The air quality in urban regions is affected by the presence of pollutants, mainly coming from combustion processes. The principal source is vehicular traffic which emits nitrogen, sulfur and carbon oxides, hydrocarbons, particulate matter, etc. into the atmosphere.

In this work the influence of the changes in traffic during holidays on the air quality of the centre of Mar del Plata city was analyzed. For this purpose continuous monitoring equipment with electrochemical sensor technology was installed, in order to determine the contaminant concentration. Simultaneously the vehicular density was measured. These measurements were performed during winter vacations and during a similar period of working days.

The obtained results allow one to determine that the air quality in the centre of Mar del Plata is not noticeably affected by the fluency of more vehicles. This was interpreted taking into account the behaviour of the tourists and local people.

The determined pollutant levels are relatively low considering the number of automobiles. This situation is usually observed in seashore cities, due to the air fluxes or "channels" formed in the street canyons, which include the street and their flanking walls [1].

Keywords: air quality, vacation period, seashore city.
\end{abstract}




\section{Introduction}

Within large urban areas the air quality is affected by substances mainly coming from the vehicular combustion processes. When these substances are above certain concentration levels they become harmful for human health. The most important contaminants are $\mathrm{CO}$ and NOx.

This work analyses the evolution of the air quality in Mar del Plata city centre during the winter holidays and also during working days.

Mar del Plata is a tourist city on the Atlantic coast, with half a million inhabitants approximately. It is located in the Southeast of Buenos Aires Province. This is the most visited city during the holidays with a great movement of automobiles in particular.

The present work is part of the research project "Study of the Air Quality in Buenos Aires Province", financially supported by the National Agency of Scientific and Technologic Promotion (Agencia Nacional de Promoción Científica y Tecnológica), Argentina.

\section{Experimental}

The polluting gases were measured by a monitoring system which included a remote station located in Mar del Plata and a Central Station which received the data by means of a cell phone system located in San Nicolás Regional Faculty. The measurements were performed by electrochemical sensor technology.

The concentrations of the contaminants $\mathrm{NOx}, \mathrm{CO}, \mathrm{HC}, \mathrm{SO}_{2}, \mathrm{O}_{3}$ were determined as an hourly average.

The equipment was located at a height of 3 meters on Mitre Street, between Belgrano and Moreno St. Figure 1 shows the location in the city centre. In this figure the orientation of the mentioned streets can be observed.

The measurements were performed during July and August in order to cover both periods: holiday time and working time.

The considered period was three weeks long taking into account the holiday corresponding to different country regions.

The vehicular traffic density was taken on the corner of Mitre and Belgrano streets. It is a typical corner of the centre of the city without traffic lights and significantly high traffic levels. It was selected due to the low presence of public transport.

\section{Results and discussion}

Figure 2 shows the hour vehicular behaviour. Little difference can be noticed on weekdays but a larger vehicular flow occurs between 12:00 and 14:00 and 19:00 and 20:00, which can be observed not only during working periods but also during vacations. This behaviour is shown in Figure 3 where the weekly averages of the vehicular flow in both periods have been represented. 


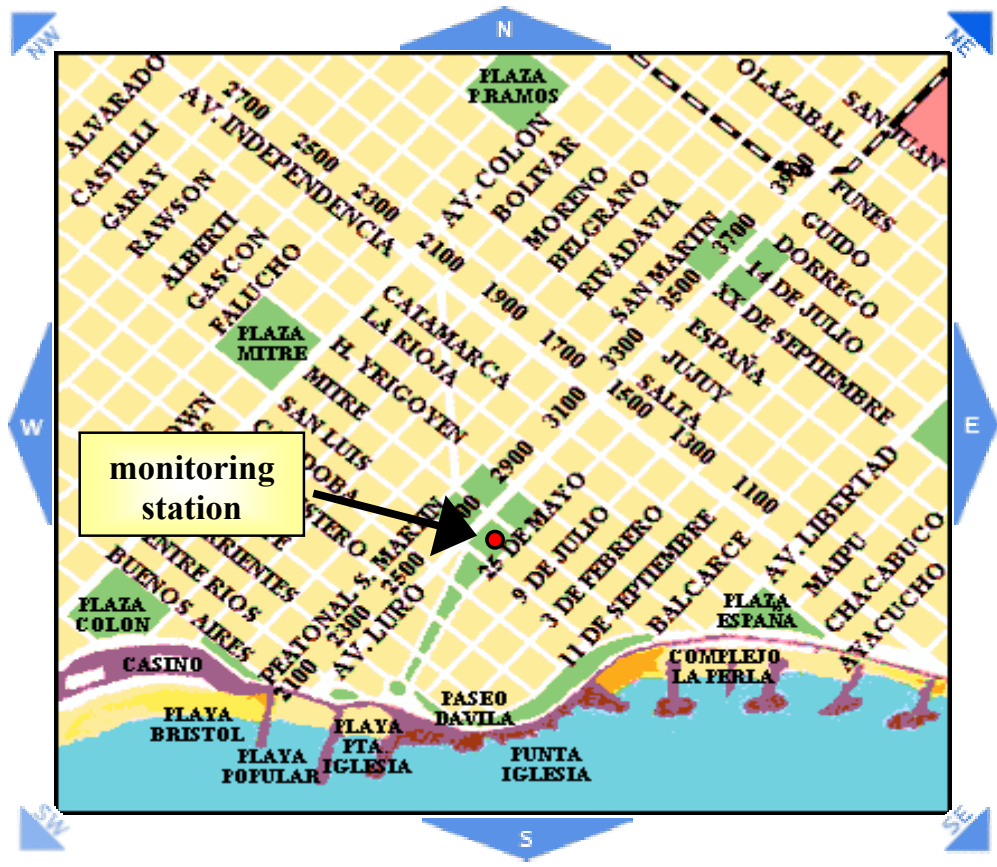

Figure 1: Equipment location in the Mar del Plata city centre.

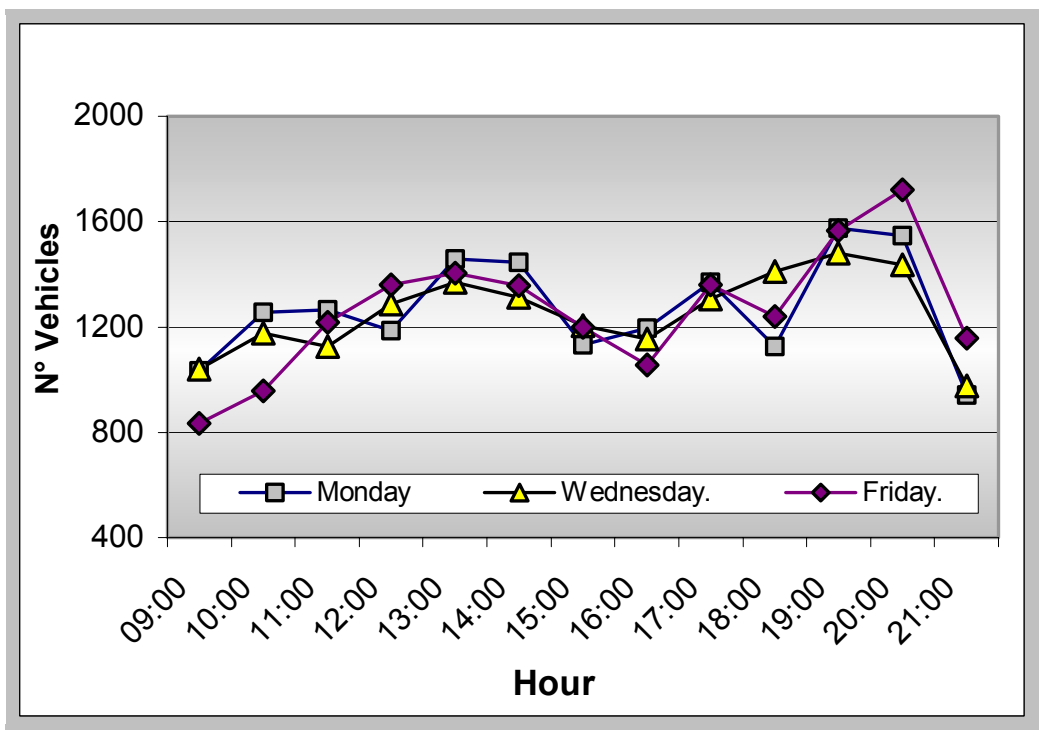

Figure 2: Hourly vehicular behaviour. Working period. 


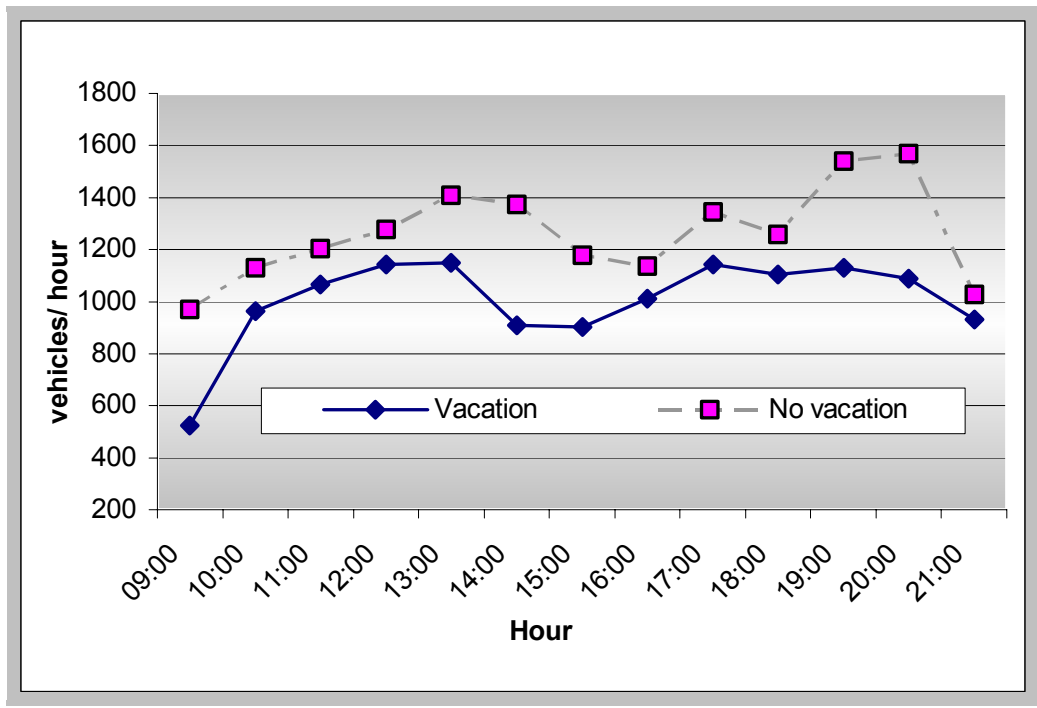

Figure 3: Vehicular flow during the working period and vacation period.

As can be observed, the vehicular density during the working period is higher than that during the vacation period, which may be due to the fact that most of the tourists do not use their vehicles in the city centre. In addition, Mar del Plata city dwellers either go away during vacations or, if they stay, avoid going to the city centre.

The place for the monitoring station was thus chosen to minimize the influence of public transport, enabling the analyses of the global results of vehicular density of vehicles such as automobiles, motorcycles and others.

Figure 4 shows the distribution of the different types of vehicles. The very small presence of buses and trucks can be observed.

The evolution of the air quality is performed by analyzing the $\mathrm{CO}$ concentration, which was taken as being most representative. The other primary contaminants analyzed showed similar evolutions. Measurements of the levels of this contaminant showed similar behaviour during the three weeks of vacation period and the four weeks corresponding to working days. Figure 5 shows the average values of these two periods.

It can be observed that during the holidays the highest levels are found at weekends and Monday, whereas on working days the highest levels are found on Thursday. Having questioned the local inhabitants it was concluded that Mondays are used by local people to do the shopping and banking business due to Mondays being the most tranquil days in relation to tourist movements. This fact explains why Mondays show the highest contamination levels during working days.

When analyzing the hourly evolution of pollutants levels it was found that the higher the traffic densities, the larger the concentrations, which occurred between 12:00 and 14:00 and 19:00 and 22:00. 


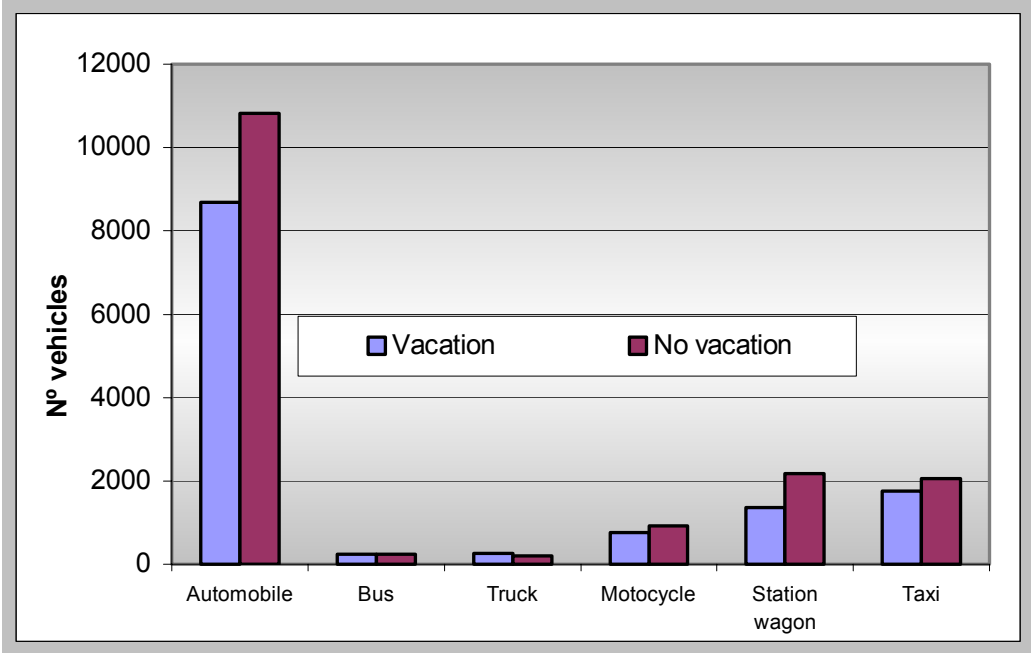

Figure 4: Distribution of the different types of vehicles in the monitored area.

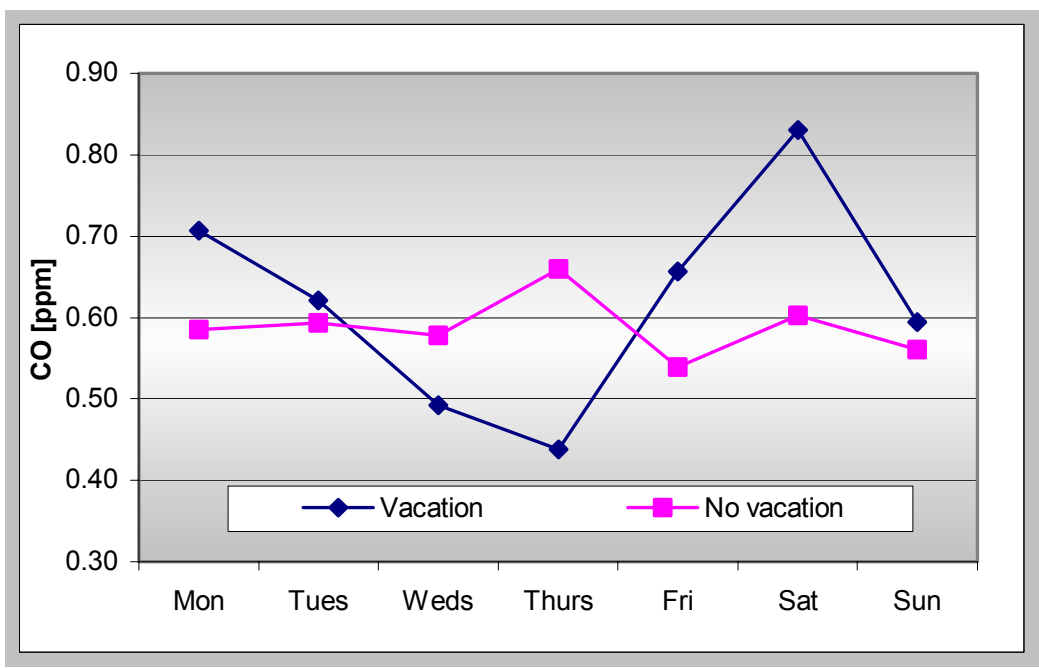

Figure 5: $\quad$ CO levels in both periods.

All of these comparisons are possible due to the fact that the meteorological conditions were stable during the measurement period. The wind direction was especially controlled.

It has been established that the influence of wind direction on the dispersion of pollutants plays an important role in the air pollution levels [2]. When the wind direction is coincident with the street orientation lower contamination levels can be expected. 
In this case study, the prevailing winds during the vacation period were NNE, NNW and ENE, and winds from NNE, ENE and SSW sectors were prevailing during August corresponding to the working period. At all times the prevailing wind directions were not parallel to the street axis, which is located on a NE-SW orientation. These directions were present a few times on the studied days. It is also important to note that the wind velocities were low during the measurements.

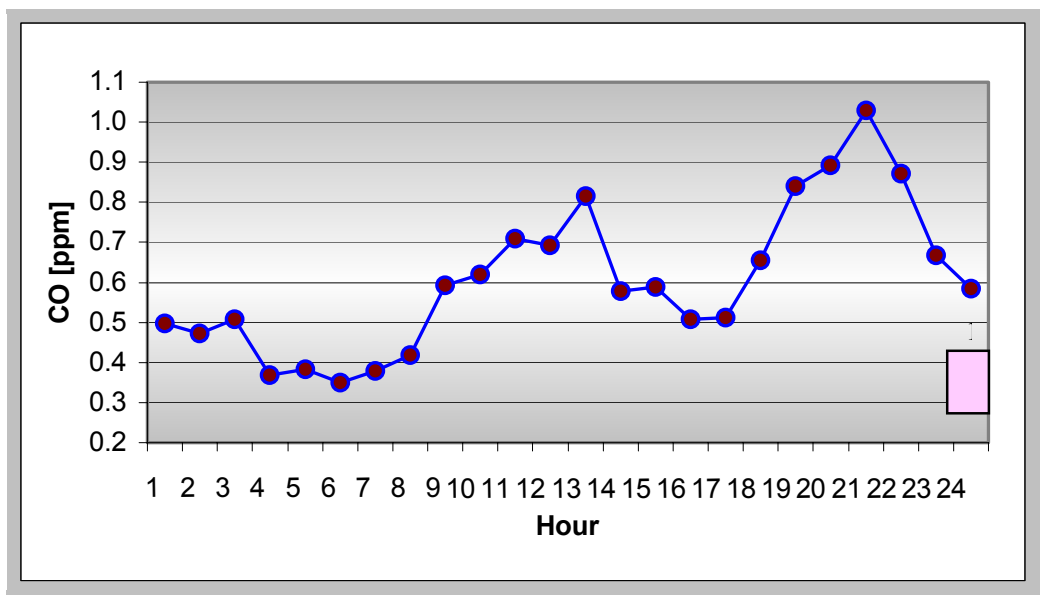

Figure 6: Hourly average of CO concentrations.

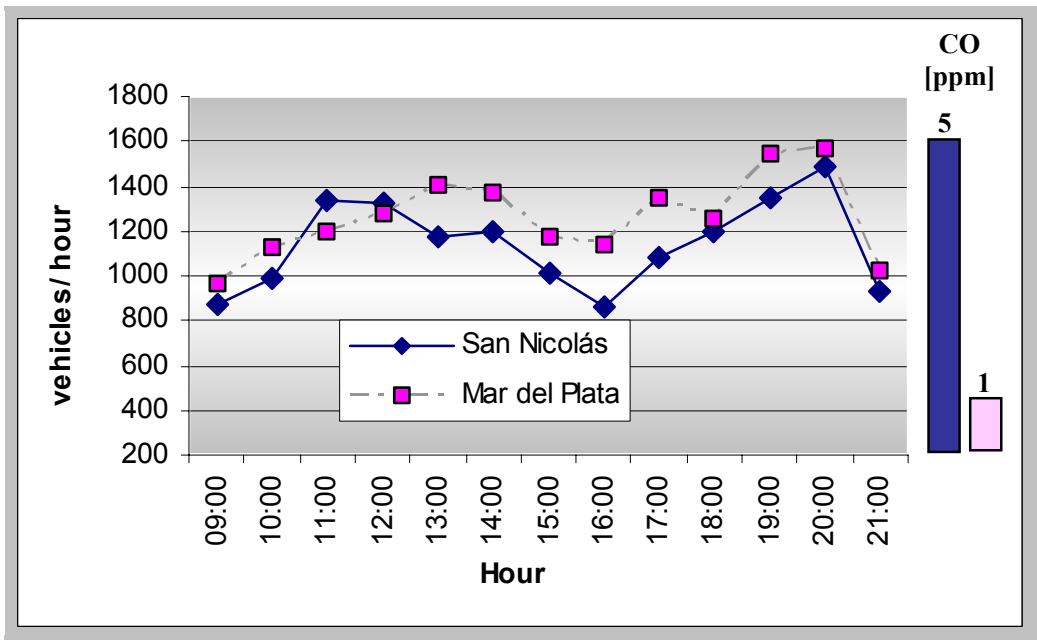

Figure 7: Vehicular density during working days in two different cities.

Figure 6 shows the $\mathrm{CO}$ concentrations expressed as an hourly average. The $\mathrm{CO}$ concentration values are relatively low when compared to the number of 
vehicles, whereas higher levels of pollution should be expected for the vehicular density measured. This is an occurrence which is common to most of the cities which, like Mar del Plata, are located on the coast where important wind channels are formed that disperse the polluting gases, with more efficiency than in cities situated in no open regions.

As a comparative example, in Figure 7 the traffic densities determined in typical streets in San Nicolás and Mar del Plata cities can be observed. Taking similar meteorological conditions and relative orientations between wind direction and streets axes, levels of CO pollutant five times higher in San Nicolás than in Mar del Plata for similar traffic densities was determined. San Nicolás is a city located in the interior of Argentina [3]. The CO concentration values in the figure, 5 and $1 \mathrm{ppm}$, are those corresponding to the San Nicolás and Mar del Plata levels respectively, for a traffic density of 1500 vehicles/hour.

\section{Conclusions}

The research performed on Mar del Plata city centre during working periods and holiday periods demonstrates that the air quality of that area is not noticeably affected by the larger fluency of vehicles. This can be explained by taking into account the behaviour of local people and tourists.

The air contaminant levels obtained are relatively low when compared to the number of vehicles being used, which is a usual occurrence in coastal cities where the wind disperses the polluting gases.

\section{Acknowledgements}

The authors wish to thank the "Agencia Nacional de Promoción Científica y Tecnológica", and the "Comisión de Investigaciones Científicas de la Provincia de Buenos Aires" for the financial support.

\section{References}

[1] T. R. Oke. "The urban energy balance” in Progress in Physical Geography. Edward Arnold Ed. (1990) pp. 471.

[2] Th. Maggos, J. Michopoulos, Ch. Vassilakos and J. G. Bartzis. "Assessment of traffic air pollution using combined traffic, air pollution and meteorological data en city of Athens". Air Pollution XII, C. A. Brebbia Ed. (2004) pp. 425.

[3] N. Quaranta, C. Grasselli and G. Merizzi. "Air quality: the influence of the economic crisis”. Air Pollution XII, C.A. Brebbia Ed. (2004) pp. 407. 